\title{
Gestational Diabetes: Exploring the Perceptions, Practices and Barriers of the Community and Healthcare Providers in Rural Bangladesh: A Qualitative Study
}

This article was published in the following Dove Press journal:

Diabetes, Metabolic Syndrome and Obesity: Targets and Therapy

\author{
Animesh Biswas (iD) \\ Koustuv Dalal $\mathbb{D}^{2}$ \\ Abu Sayeed Md Abdullah' \\ AKM Fazlur Rahman ${ }^{3,4}$ \\ Abdul Halim ${ }^{1,5}$

\begin{abstract}
'Reproductive and Child Health Department, Centre for Injury Prevention and Research, Bangladesh (CIPRB), Dhaka 1206, Bangladesh; ${ }^{2}$ Department of Public Health Science, School of Health Sciences, Mid Sweden University, Sundsvall, Sweden; ${ }^{3}$ Centre for Injury Prevention and Research, Bangladesh (CIPRB), Dhaka I206, Bangladesh; ${ }^{4}$ Bangladesh University of Health Sciences (BUHS), Dhaka, Bangladesh; ${ }^{5}$ Kumudini Medical College, Tangail, Bangladesh
\end{abstract}

Background and Objective: Gestational Diabetes Mellitus (GDM) is a prevalent and important disease during pregnancy and has detrimental effects on both the mother and the baby. The current study explored the perception and attitude of the community people about GDM and describes the challenges and gaps in knowledge, availability and accessibility of services for GDM screening and management at a rural community in Bangladesh.

Methods: We performed a qualitative study including seven Focus Group Discussions (FGDs) and eight Key Informant Interviews (KIIs) from November 2017 to January 2018 at randomly selected areas of Tangail district. A highly trained team including two anthropologists conducted the qualitative studies (FGDs and KIIs) under the guidance of experienced researchers. Thematic analysis was performed.

Results: GDM is not a known term for pregnant women, their husbands, mothers, and mothers-in-law. Most of the participants $(78.7 \%)$ did not even hear the term. Some of them $(25.5 \%)$ perceived that GDM will persist for whole life and transmit from husband to wife and mother to baby. Some people $(21.3 \%)$ thought that GDM entirely depends on the wish of the God. Most of the participants $(68.1 \%)$ perceived that symptoms of other types of diabetes and GDM are almost the same. Some participants (19.1\%) thought that GDM patients need to intake some medicines that might affect the fetus. The majority of the respondents $(83 \%)$ had no idea when a pregnant woman should test her diabetes during pregnancy. If GDM diagnosed, pregnant women decided to follow the advice of the doctors. The results from KII with health managers found that they lack in-depth knowledge of GDM. There is no structured guideline or protocol at their facilities for GDM management.

Conclusion: The existing barriers at the communities for adequate detection and management of GDM are identified properly. The findings of this study will be helpful for the decision-makers in taking necessary actions to control the GDM.

Keywords: gestational diabetes, community, practices, challenges, Bangladesh

\section{Introduction}

Bangladesh is one of the top ten countries in the world for the burden of diabetes which will be double in the next 20 years. ${ }^{1,2}$ The current prevalence of diabetes in Bangladesh is $5.5 \%$. It is expected to rise to $8.2 \%$ by $2030 .^{3}$ During pregnancy, any degree of glucose intolerance is commonly known as Gestational Diabetes Mellitus (GDM). ${ }^{1-4}$ The prevalence of GDM ranges from $8.2 \%$ in rural
Correspondence: Koustuv Dalal Department of Public Health Science, School of Health Sciences, Mid Sweden University, Sundsvall, Sweden

Tel +46725932995

Email koustuv.dalal@miun.se 
Bangladesh to $12.9 \%$ in urban Bangladesh. ${ }^{4,5}$ More than two million people have diabetes but are yet undiagnosed in Bangladesh. ${ }^{3}$ Undiagnosed cases of women with diabetes in pregnancy are a crucial concern in Bangladesh, regarding healthcare access and nutrition. ${ }^{6}$ Women often do not receive treatment for sickness or seek care from unqualified practitioners. ${ }^{7}$ In Bangladesh, the management of GDM patients has considered a national maternal and neonatal health guideline, but there is no routine screening of all pregnant patients for GDM. ${ }^{8,9}$ Only $55 \%$ of pregnant women access antenatal care (ANC) services, ${ }^{10} 45 \%$ of pregnant women would remain undetected for GDM in Bangladesh. Pregnant women in Bangladesh do not necessarily attend the ANC between 24 and 28 weeks gestational phase. ${ }^{10,11}$ Uncertainty about the date of the last menstrual period renders gestational age estimation difficult for the women. ${ }^{11}$ Palpation alone might be unreliable particularly in the case of a large baby or polyhydramnios; which are known complications of the GDM. ${ }^{12}$ GDM screening is not frequently performed, particularly in rural areas under the lower levels of the health care facilities. ${ }^{13}$ A study in India found that only $17.5 \%$ of women had good knowledge of GDM where the significant sources of awareness are the television, radio, neighbours and family members. ${ }^{14}$ Awareness of the GDM plays a vital role in the prevention and early diagnosis of the diseases. ${ }^{14,15}$ The existing community network can be used to refer all pregnancies identified at the community level for ANC booking and GDM screening to the facilities. ${ }^{16}$ The current study explored the perception and attitude of the community people about GDM and describes the challenges and gaps in knowledge, availability and accessibility of services for GDM screening and management at a rural community in Bangladesh.

\section{Methods}

\section{Study Design}

The study applied qualitative methods including Focus Group discussions (FGDs) and key informant interviews (KIIs) from November 2017 to January 2018 at the randomly selected areas of Tangail district. FGDs and KIIs guidelines were developed by experienced researchers. A team of six survey assistants was constituted including two experienced anthropologists, for data collection. Two days of training were provided among the study team. A pretest was done before the data collection.

\section{Sample}

In total eight KIIs were conducted with the health managers at district and sub-district level healthcare facilities. A primary, one secondary and one tertiary healthcare centers were selected to conduct the KII with the managers of those facilities.

The study selected three groups of participants for conducting FGDs include pregnant women, husbands and mothers-in-law or mothers of pregnant women. Seven FGDs were conducted in total. Two FGDs with the husband groups, two with mother or mothers-in-law groups and three with pregnant women groups were conducted. All participants were related to the pregnant women, so, their knowledge, perception, opinion and willingness were directly related to the study objectives. Each FGD was comprised, 5-8 respondents. During rapport building with the communities, researchers carefully selected FGD participants (Table 1).

\section{Prompt of KII}

For conduction of the KII, several areas were considered to interview the managers. These areas include Role and responsibility regarding MNC services, Collaboration of NCD program/services with/through MNH services, understanding of

Table I Description of the Study Methods

\begin{tabular}{|l|l|l|l|}
\hline $\begin{array}{l}\text { Study } \\
\text { Design }\end{array}$ & Method & Participant & $\begin{array}{l}\text { Agetal } \\
\text { Range }\end{array}$ \\
\hline $\begin{array}{l}\text { Qualitative } \\
\text { study }\end{array}$ & $\begin{array}{l}\text { Key Informant } \\
\text { Interview (KII) }\end{array}$ & $\begin{array}{l}\text { Civil Surgeon (CS), Deputy Director, Family planning (DDFP), Upazila Health and Family } \\
\text { planning Officer (UH\&FPO), Upazila Family planning Officer (UFPO), Director of Kumudini } \\
\text { Hospital, Consultant of Kumudini Hospital, Residential Medical Officer (RMO) of Upazila } \\
\text { Health Complex (UHC), Consultant (Medicine) of UHC }\end{array}$ & $\begin{array}{l}\text { 30-56 KIls } \\
\text { years }\end{array}$ \\
\hline $\begin{array}{l}\text { Qualitative } \\
\text { study }\end{array}$ & $\begin{array}{l}\text { Focus Group } \\
\text { Discussion (FGD) }\end{array}$ & $\begin{array}{l}\text { Pregnant woman (03 FGD-20 pregnant women), Mother and Mother- in law (02 FGD with } \\
\text { 20-50 } \\
\text { years }\end{array}$ & \begin{tabular}{l} 
FGDs \\
\hline
\end{tabular}
\end{tabular}


GDM, any guidelines, infrastructures, preventive or clinical services regarding GDM exists and recommendations to improve the community awareness relating to GMD (Table 2).

\section{Prompt of FGD}

For each FGD, participants assured their participation in a convenient time and venue. A neutral place like community health centre was considered for venue selection. To avoid personal influence, we did not select any site in any of the respondent's house. A facilitator and a note-taker conducted each FGD. The facilitator attended the session using a guideline, ensuring everybody's active participation. The note-takers primary responsibility was to take hand notes and to audio record the session. She was responsible for the sitting arrangement of the participants. Each FGD session continued for 40-60 minutes. A total number of 47 people including 20 pregnant women ( 3 FGDs), 13 mothers \& mothers-in-law (FGDs) and 14 husbands (2 FGDs) had participated in these seven FDGs (Table 3).

\section{Data Analysis}

The qualitative data was analyzed according to the standard guideline, and the final summary was prepared to incorporate with the quantitative findings. By reviewing the data, a code list was prepared. Written consent was taken from each of the respondents before the interviews or FGDs. Several prompts were used to obtain information. Audio voice recording was done before permission

Table 2 Description of the Areas of Discussion for KII Conduction

\begin{tabular}{|c|c|}
\hline Areas of Discussion & Types of Prompts Used \\
\hline $\begin{array}{l}\text { Role and responsibility regarding } \\
\text { maternal and neonatal care services }\end{array}$ & $\begin{array}{l}\text { Primary responsibilities regarding maternal and newborn care? } \\
\text { How long do you work here? }\end{array}$ \\
\hline $\begin{array}{l}\text { The collaboration of non- } \\
\text { communicable diseases (NCD) } \\
\text { program/services with/through } \\
\text { maternal and neonatal health } \\
(\mathrm{MNH}) \text { services }\end{array}$ & $\begin{array}{l}\text { Is there any program in your area to address NCDs? } \\
\text { Which NCDs are addressed? } \\
\text { Any preventive or curative facility health services/programs regarding GDM or Diabetes now or in the } \\
\text { recent past? } \\
\text { Is there any screening and follow up programs for GDM/Diabetes? } \\
\text { Experiences and also the challenges of implementing such programs. }\end{array}$ \\
\hline $\begin{array}{l}\text { Understanding on gestational } \\
\text { diabetes (GDM) }\end{array}$ & $\begin{array}{l}\text { What do you know about GDM? } \\
\text { Is there any risk of developing GDM? } \\
\text { Do you know about any complications GDM may cause in mothers and babies? } \\
\text { Is there any test to detect GDM? } \\
\text { Is there any treatment for GDM? When should you test for GDM? }\end{array}$ \\
\hline Guidelines & $\begin{array}{l}\text { Any guidelines for } \mathrm{MNH} / \text { pregnancy care for facilities or community? } \\
\text { Are GDM and Diabetes in pregnancy included in these guidelines? } \\
\text { Management recommendations of GDM/diabetes in pregnancy of these guidelines? }\end{array}$ \\
\hline $\begin{array}{l}\text { Preventive or clinical services } \\
\text { regarding GDM exists in your } \\
\text { Upazila/district }\end{array}$ & $\begin{array}{l}\text { Any register in the facilities to record diabetes or GDM while patients are attending your facilities? } \\
\text { Are there any organized service facilities regarding GDM for: screening/treatment/referral/follow up? } \\
\text { Who provides this service? } \\
\text { Do health care providers (HCPs) have adequate skills/knowledge to manage GDM? }\end{array}$ \\
\hline Infrastructure & $\begin{array}{l}\text { Is there any diabetes care corner/centre available in this health centre: screening for diabetes, follow-up, } \\
\text { insulin treatment? } \\
\text { Are there any information, education and communication (IEC) materials available? } \\
\text { Is there a laboratory facility available at your centre for checking diabetes? } \\
\text { What are the tests available? How about nutritional advice for GDM? } \\
\text { Who provides this advice? Any emergency drugs at your center? }\end{array}$ \\
\hline Recommendation & $\begin{array}{l}\text { Anything to improve the health facilities for better services to pregnant women for GDM screening and care? } \\
\text { What do you think about a community level facility for screening and follow up GDM patients? } \\
\text { How to raise awareness of GDM and its screening and management in the community? } \\
\text { What suggestions to improve awareness of community people on GDM, quality seeking care and ensure access } \\
\text { to screening, counseling, treatment and follow up services for women with diabetes in pregnancy or GDM? }\end{array}$ \\
\hline
\end{tabular}


Table 3 Areas of Discussion for FGD Conduction

\begin{tabular}{|c|c|c|}
\hline Areas of Discussion & Types of Prompts Used (Pregnant Women) & $\begin{array}{l}\text { Types of Prompts Used (Husband/Motherl } \\
\text { Mother in Law) }\end{array}$ \\
\hline $\begin{array}{l}\text { Knowledge and practices on } \\
\text { Antenatal and Neonatal care }\end{array}$ & $\begin{array}{l}\text { Describe the problems faced by pregnant women } \\
\text { What should be done with a pregnant woman in } \\
\text { terms of treatment and health care? } \\
\text { What are the danger signs in pregnant women and } \\
\text { newborns? } \\
\text { What are the common practices for the treatment of } \\
\text { those problems? } \\
\text { If pregnant women or children need extra nutritional } \\
\text { food and care, how is this done? }\end{array}$ & $\begin{array}{l}\text { Describe the problems faced by pregnant women and } \\
\text { what need to be done for their treatment and health } \\
\text { care? } \\
\text { What are the danger signs of pregnant women and } \\
\text { newborns and, how are those problems treated? } \\
\text { Either pregnant women or children need extra } \\
\text { nutritional food and care, if yes then how? }\end{array}$ \\
\hline $\begin{array}{l}\text { Existing health care facilities on } \\
\text { Antenatal and neonatal care \& } \\
\text { coverage of health facilities }\end{array}$ & $\begin{array}{l}\text { Did any health workers or other related people visit you } \\
\text { while you are pregnant and after the birth of your child? } \\
\text { If yes then who are they, what they have told you? } \\
\text { Can you please name the health facilities in the locality } \\
\text { that provide maternal health care and nutrition care? } \\
\text { How far are those centres from your home, type of } \\
\text { postnatal care (PNC) and other maternal health } \\
\text { services available in the community? } \\
\text { Do you/mothers of this locality visit the facilities in need? } \\
\text { What portion of your community gets the facilities for } \\
\text { maternal neonatal and child health (MNCH)? } \\
\text { What do you suggest improving the health facilities for } \\
\text { ensuring access of community? }\end{array}$ & $\begin{array}{l}\text { Did any health workers or other related people visit } \\
\text { the pregnant woman? If yes, then who were they? } \\
\text { Can you please name the health facilities in the } \\
\text { locality that provide postnatal, other maternal health } \\
\text { care and nutrition care? } \\
\text { How far are those centres from your home, type of } \\
\text { postnatal care (PNC) and other maternal health } \\
\text { services available in the community? } \\
\text { What portion of your community gets the facilities } \\
\text { for maternal neonatal and child health (MNCH)? } \\
\text { What do you suggest improving the health facilities } \\
\text { for getting to your community? }\end{array}$ \\
\hline Barriers & $\begin{array}{l}\text { What are barriers to seek maternal health and } \\
\text { neonatal care from the local health care centres? } \\
\text { (Probe for Transport, distance, charges, lack of } \\
\text { medicine, waiting time, doctor's quality and } \\
\text { behaviours, lack of equipment and other facilities, lack } \\
\text { of bad, space constraints and so on) }\end{array}$ & $\begin{array}{l}\text { What are barriers to seek maternal health and } \\
\text { neonatal care from the local health care centres? } \\
\text { (Transport, distance, charges, lack of medicine, } \\
\text { waiting time, doctor's quality and behaviours, lack of } \\
\text { equipment and other facilities, lack of bad, space } \\
\text { constraints and so on) }\end{array}$ \\
\hline Impact and satisfaction & $\begin{array}{l}\text { Either you benefited from the services at the health } \\
\text { facilities you seek care? If yes, then how? } \\
\text { How you or your children's life affected from this? } \\
\text { Please tell us the details. } \\
\text { What are the most effective services of the health } \\
\text { care centre that benefited you most? } \\
\text { What is your opinion about the service quality of local } \\
\text { health care centres and community workers? Were } \\
\text { you satisfied with the services? } \\
\text { If yes, then how and why; and if not satisfied, then why } \\
\text { and how could the facilities be improved? }\end{array}$ & $\begin{array}{l}\text { How the pregnant women were benefited from the } \\
\text { health centre? Please tell us the details. } \\
\text { What are the most effective services of the health } \\
\text { care centre? } \\
\text { What is the service quality of local health care } \\
\text { centres and community workers? } \\
\text { How to improve the health facilities? }\end{array}$ \\
\hline Recommendations & $\begin{array}{l}\text { How could the people in your community know more } \\
\text { about the health facilities more effectively? } \\
\text { How do we improve the services, so that every } \\
\text { community in hard to reach areas can be under cover } \\
\text { by health coverage? } \\
\text { How can we motivate people and make it easier for } \\
\text { them to access health facilities? } \\
\text { What happens if the intervention program will be } \\
\text { expired? }\end{array}$ & $\begin{array}{l}\text { How could the people in your community know more } \\
\text { about the health facilities more effectively? } \\
\text { How do we improve the services, so that every } \\
\text { community in hard to reach areas can be under cover } \\
\text { by health coverage? } \\
\text { How can we motivated and can able to make people } \\
\text { come to more to get health facilities? } \\
\text { What happens if the intervention program will be } \\
\text { expired? }\end{array}$ \\
\hline
\end{tabular}


from the respondents. From the audio-recordings and hand notes of the interviewer's, the research officers prepared IDIs and FGDs transcripts in native Bengali language. Later, translations of the transcripts were done. Two senior researchers from randomly selected transcripts reviewed the quality of the transcripts. Peer debriefing also performed to maintain its reliability of the data. Initial open coding was done, and then from those open codes, selective coding was done. Themes were identified after reading and re-reading the data ${ }^{17,18}$ and finally, the analysis was performed thematically.

\section{Ethics and Consent}

The national ethical review committee of CIPRB has approved this study under "Bagan Mayer Jonno" intervention (Memo- CIPRB/ERC/2017/20, Date-15 June 2017). Verbal and written informed consents were received from each of the respondents before the interview. The study was conducted in accordance with the Helsinki Declaration.

\section{Results}

The community people have the perception of diabetes, but they have limited ideas on Gestational diabetes. They have no ideas about the difference between diabetes and gestational diabetes. The knowledge of GDM was found among those who suffered, or if their family members or friend and neighbours suffered from GDM. Though they have limited ideas on the place of conducting the test and receiving treatment of GDM, they could not afford it, for financial constraint and lack of awareness.

\section{Communities Perception of GDM General Community Perception of GDM}

GDM is not a known word for the participants. Most of the participants did not even hear of it. They perceived that diabetes may occur at any age, even during pregnancy. Though few participants had ideas on it, they did not know how it is different from other diabetes. Though few participants had ideas on it, but they did not know how it is different from other diabetes. The study found that almost all respondents have no clear perception on GDM rather have some misperception. Most of the participants perceived that GDM and other types of diabetes mostly differ from the level of suffering. Some perceived that all types of drugs should not be consumed during pregnancy (Figure 1).

'When a person has diabetes, she/he has to suffer it alone. But when a pregnant woman has diabetes, she has to suffer it along with her child. So, the level of suffering is different here.' -P33 (One of the mothers-in-law) said.

'There are several types of diabetes. Even diabetes can transform from husband to wife or from wife to husband.'P41 (One of the mothers-in-law) mentioned.

'A general diabetes patient can take medicine to control her/his diabetes but a GDM patient cannot take medicine

Key findings from the community

Perception and practices on GDM

1. Minimum perception and knowledge on gestational diabetes

2. No idea about the difference between diabetes and gestational diabetes

3. Lots of misperception on the causes of gestational diabetes

4. Majority of them perceive that if diabetes occurs during pregnancy it must be affected to the newborn

5. Tiny knowledge was found among those who suffered from GDM or whose family members or friends or neighbors suffered from GDM. They know that GDM might be cured after delivery

6. Lack of knowledge and ideas on GDM test and treatment. They do not even know the place and provider Challenges for conducting the GDM tests and treatment.

1. The most important challenges are the lack of awareness among the community people on GDM

2. The communication gap among the HCPs and community people regarding GDM

3. Financial constraint is one of the major challenges to receive treatment from the qualified provider at the target facilities

Way forward

1. Almost all of the participants are willing to undergo GDM test and treatment if they get support.

2. Community people expected all financial support for the treatment of GDM

3. They also prefer the government facilities (Community Clinic, Upazilla Health Complex and District Hospital) to conduct GDM test and receive treatment.

4. They mostly prefer the welfare-hospital (not-for-profit) at Tangail for conducting the GDM test and treatment as they believe they will get specialist doctors and good diagnosis and treatment facilities.

5. They suggest conducting GDM test during receiving ANC to ensure test for every pregnant woman

Figure I Key findings from the community. 
because it may create risk for her baby.'- P18 (One of the pregnant women) mentioned.

\section{Perception of the Practices During GDM}

The participants perceived that physical exercise is necessary to control diabetes which is not possible for the pregnant women, therefore, they observed that GDM is more problematic than other diabetes. Mothers have to suffer in the long run. Few participants mentioned that the diabetic-patients should consume a balanced diet, which is almost impossible for the pregnant women as they need proper nutrition for the fetuses and for themselves. Moreover, physical exercise and more walking are not easier during pregnancy period. So, participants are quite confused and concerned to control GDM.

"Diabetic patient has to walk regularly, but it is difficult for a GDM mother to walk frequently."- P11 (One of the pregnant women) mentioned.

"Because of diabetes, a pregnant woman does not eat enough food. When the mother does not eat properly, the fetus will not get enough nutrition."- P25 (One of the husbands) mentioned.

"It is difficult to maintain a diabetic diet chart for pregnant women diagnosed with GDM because they have to take nutritious food. So, they can't eat only bread or a little amount of food. Mother nutrition is directly related to her child's nutrition during her pregnancy." - P13 (One of the pregnant women) mentioned.

\section{Perception of the Causes and Risk Factors of GDM}

Most of the participants have no idea about the causes and risk factors of GDM instead, they wanted to know from us. However, there are some misperceptions about the risk factors for GDM. Some of them perceived that women suffer from GDM because of their food habits. If they eat more sweets or foods made from sugar, then they have the risk to suffer from diabetes. Some also perceived that pregnant women might suffer from disease due to hereditary reasons. Few people thought that it entirely depends on the wish of God.

"It's all about the desire of Allah; we have no control over it". - P 34 (One of the mothers-in-law) mentioned.

"During pregnancy, the consumption of excess sugar contained food is one of the major risk factors of GDM."P 28 (One of the husbands) mentioned.
"If the father or mother of a pregnant woman has diabetes, then there is a possibility that she may also have the GDM." - P 18 (One of the pregnant women) mentioned.

"I am a GDM affected patient and take insulin three times a day. Because the doctor told that pregnant woman should not take any other medicine for diabetes which will be harmful to me. The doctor also told me to take nutritious food in a specific amount and to walk slowly for a few minutes at home." - P14 (One pregnant woman diagnosed with GDM) shared her experience.

\section{Perception of the Symptoms and Complications of GDM}

Most of the participants had no or little ideas on the symptoms of GDM. Some participants mentioned symptoms of GDM include frequent urination, loss of body weight, loss of appetite, blurred vision, the problem in eyesight and kidney. Few participants mentioned that the desire for food, especially for sweets would increase among GDM patients. Most of the participants perceived that symptoms of other types of diabetes and GDM are almost the same. Some participants had limited ideas on complications of GDM. Some of them perceived that if GDM affected pregnant women deliver by Caesarian section, then it is difficult for her to recover.

"A pregnant woman with GDM has a major symptom of frequent urination. She may have become weak gradually. Her appetite for food, especially for sweets will increase." - P 15 (One of the pregnant women) mentioned.

"If a pregnant woman suffers from GDM, she may have a complication during delivery, and if she goes for a caesarean section, then there is a risk to recover her stitches. It will take a long-time even gangrene may occur."- P 27 (One of the husbands) mentioned.

\section{Perception of GDM Effect on the Fetus}

Almost all participants agreed that if women suffer from GDM, it would be harmful to both the mother and her fetus because children directly linked with the mother during pregnancy. Though they do not know precisely the type of problems creates but fear about it. Most of them think thought the GDM affected the mother to deliver the baby with diabetes, jaundice, pneumonia, typhoid and several other diseases. Few of them perceived that a child might die immediately after delivery or intrauterine death may happen. Some participants thought that GDM patient has to take some medicines that might affect the 
baby. Very few respondents were concerned about the nutritional value of the fetus among the GMD affected mother.

"I have a relative whose child has died immediately after delivery. Mother was in trouble for both diabetes and high blood pressure. She \& her family member noticed it just before delivery. Mother was hospitalized for one month, and now the mother is ok. So, it is dangerous for that baby, and we are scared about it."- P12 (One of the pregnant women) mentioned.

"A few days ago, a child was born with diabetes, though his mother does not have diabetes at all. Then the doctor said that his paternal grandfather has diabetes, so the baby carries it by hereditary."- P39 (One of the mothers-in-law) mentioned

N.B. Here doctor means the quack. (rural medical practitioner)

"The fetus may receive less nutrition from the mother because the GDM affected the mother has to maintain her food. So, the child may be born with lower intelligence with the disability."- P23 (One of the husbands) mentioned.

\section{Practices and Health Seeking Behaviour on GDM}

\section{Perception of the GDM Test}

The majority of the respondents have no idea in which time a pregnant woman should test her diabetes during pregnancy. Very few respondents perceived that the test should be performed during the time of the $4^{\text {th }}-5^{\text {th }}$ months of pregnancy but were not confirmed. Some of them said that GDM has the same pathological test like other types of diabetes. Most of them do not have a clear idea about the available facilities for GDM treatment. Some of them perceived that GDM can be identified by testing blood or urine. According to their views, the lab technicians, doctors, nurses are responsible for doing the test depending on the particular hospital's facilities. Few of them told that private clinics and hospitals like City Hospital, Kumudini hospital and diabetes hospital may have GDM test facilities.

"GDM test only occurs at the district hospital by the technician and doctor where Blood and Urine need to test for diagnosis of GDM.”- P 24 (One of the husbands) mentioned

"We can't identify exactly how GDM is different from other types of diabetes, so we can't understand whether the test period is different or not." - P 12 (One of the pregnant women) said.

\section{Perception of the Place and Providers of GDM Treatment}

Participants have no clear ideas on the location for the of GDM. Most of the respondents perceived that government hospital will be the best place for treatment. They prefer District Sadar Hospital for GDM treatment as they think there are specialists and the test and treatment costs are lower than any private health clinic or healthcare facilities. Some respondents prefer a welfare-hospital (not-for-profit) at Tangail for GDM treatment as they believe it and know that there are many expert and specialist physicians for getting proper treatment without monetary exploitation. Few of them preferred private clinics for the GDM treatment as they can receive quicker handling there but many of the respondents disagreed with this issue.

"The diagnosis and treatment facilities of district Sadar Hospital are very good. So, we rely mostly on this hospital and its expert physicians. We also prefer the district hospital to get better treatment from a qualified provider."P17 (One of the pregnant women) mentioned.

N.B. The hospital referred here is a well-known welfarehospital (not-for-profit) at Tangail.

"Private clinics provide us quick treatment, but it is expensive. Moreover, there are limited doctors and treatment facilities in a private clinic." - P28 (One of the husbands) said.

\section{Barriers to Practice GDM Management in Communities}

Misperception on GDM persisted among the participants. Many of them told that GDM is never cured properly. Some pregnant women mentioned that GDM would cure after delivery. Lack of community awareness on GDM and limited communication with government healthcare providers regarding GDM is one of the major constraints. They informed that there is no support from Government and private organizations for GDM in their neighbourhoods and adjacent areas. Although some of the respondents mentioned a GDM project at the welfare-hospital (not-for-profit) at Tangail, where a midwife test and counsel on GDM. They also mentioned that in that welfare-trust-hospital (not-forprofit) and at the district hospital at Tangail, the patients need to wait about one hour to meet with a doctor and at least two-three days to find pathological test results. They also expect the authority to look after this time-consuming process. One of the most critical challenges is financial constraints for the test and treatment of GDM. 
'GDM will be fully cured after the birth of the child. I have seen it from my relative's experience.'- P24. (One of the husbands mentioned)

"We didn't hear about GDM from any health workers. But I think GDM is a communicable disease. So, it occurs from husband to wife and mother to newborn." - P38 (One of the mothers-in-law) mentioned.

"GDM has an economic impact as a test and treatment of GDM is expensive. It is difficult to maintain the cost of treatment, medicine and surgery (if needed) of GDM patients because it is a complicated issue." - P7 (One of the pregnant) women mentioned.

\section{Communities' Recommendation to Overcome the Barriers on GDM}

According to some respondents, it is essential to early detection, treatment and prevention of GDM. They also expect the test and treatment support at the facilities in their neighborhoods. Upazilla (sub-district) Health Complex, Community Clinics are preferable to them. Some of them even mentioned about the local family healthcare centers or any other nearest health clinic. Participants also agreed to have the GDM tests and treatments if they receive the necessary supports from the facilities. If GDM diagnosed, they agreed to follow the advice of the medical doctors.

"If we get the GDM related health services within the locality, our time and money will be saved."- P22 (One of the husbands) mentioned.

'I will go anywhere for the treatment of my daughter-inlaw if she affected by GDM because her health condition is directly related to her baby in the womb.' - P31 (One of the mothers-in-law) mentioned.

\section{Health Manager's Views on GDM at Communities}

Most of the participants (health managers) informed that they know GDM but they do not have in-depth knowledge. The clear perception was found among the consultant physicians and RMOs who are directly dealing with diabetic patients. About the complication of GDM, the responders mentioned that the mother has a chance to gain more weight, abortion, complications during delivery and GDM children may become atypical and diabetic. Most of the participants said that blood and urine test is recommended for early detection for GDM but could not mention any specific name of blood and urine test. There is a gap in knowledge sharing between health managers and HCPs. Some of them told that blood sugar level is needed and fewer said about OGTT, corresponding urine sugar for GDM detection. One of them said the urine albumin test is necessary to diagnose GDM.

"We know about GDM but don't practice on it. There is a lack of facilities and specialist on GDM. The GDM is an important topic for pregnant women, and we should concern on it."- One of the district health managers mentioned.

"Vast ideas are essential on GDM, especially about the predisposing cause and prevention of GDM. If our HCPs have limited knowledge, then they can't convey the right message to the community."- One of the district health managers mentioned.

"Not only endocrinologists but gynecologists also need to involve in detecting and managing GDM mother. The GDM mothers should deliver at healthcare facilities to avoid pregnancy-related complications." - One of the health managers mentioned.

\section{Gaps and Challenges in GDM Management}

Participants said that there is no structured guideline or any protocol at their facilities on GDM or related to diabetes. Almost all participants said the main barrier towards GDM care service is that they do not have any clear idea, training or workshop on GDM. So, they lack the necessary information about it. They also said that logistics and other facilities regarding GDM are not available. Few respondents mentioned that unavailable doctor at a community clinic and FWC is a given barrier for managing GDM patients. According to the managers, there is a lack of facilities, trained providers and limited drug supplies for GDM patients in the facilities. There are scarce registration books and other documents for GDM patients in the facilities.

"There are no GDM corners and quality laboratory facilities for testing GDM. We don't have any structured guidelines on GDM testing. The HCPs are not trained on GDM." - One of the district health managers mentioned.

"We don't have any GDM corner for these patients, but I'm very interested in it. We want to serve GDM patients to reduce the mortality and morbidity of mothers and new borns." One of the health managers mentioned. 


\section{Way Forward}

All managers mentioned the proper training on GDM required for the HCPs for understanding it properly. The community HCPs need to know the exact cause, treatment, complications of GDM. They also emphasized the community-level awareness programs which are essential to motivate the community people about the importance of GDM. Most of the participants asked for a structured GDM protocol or guideline to ensure the GDM detection, treatment and follow up. One of the participants said if endocrinologist could ensure GDM management, then it will be more beneficial.

"Gestational Diabetes is a vital issue to reduce MMR and NMR, so structured work should be done on it."- One of the district health managers mentioned.

"Increase awareness programs for the community people and some training and awareness programs for HCPs are mainly required." - One of the health managers mentioned.

"It is essential to organize awareness programs and the mothers' assembly on GDM. Courtyard meetings, leaflet, festoon and public announcing can be used for community awareness on GDM."- One of the health managers mentioned.

\section{Discussion}

The study found that the rural communities perceived that diabetes may occur at any age even during pregnancy. Most of them cannot understand that GDM is different from other diabetes. Some pregnant women know about GDM, but almost the entire husband and mothers-in-law do not have a perception, and some have a misperception about it. The participants perceived that physical exercise is necessary to control diabetes which is not possible for pregnant women. That's why they understood GDM is more problematic rather other diabetes and mother have to suffer in the long run.

There are limited facilities in the hospital to practice on GDM management. They do not have any clear idea, training or workshop on GDM. All healthcare managers mentioned about the proper training of HCPs required on GDM to understand it properly. Similar results were found in another study where it was emphasizing evidence-based GDM management, and access to specialized knowledge is important. ${ }^{19}$

The current study found that the proper training of HCPs required on GDM to understand and disseminate the knowledge adequately in the community and to find out the exact cause, treatment, complications of GDM which is similar to another study from Africa. ${ }^{20}$

The study found that there is no structured guideline or any protocol at their facilities on GDM or related to diabetes. Almost all participants said that the main barrier towards GDM care service is that the lower level healthcare staff may not have a clear idea and training on GDM. The national report of Bangladesh also supports these findings. A national maternal and neonatal health guideline has been proposed by the Ministry of health and family welfare, Bangladesh for the systematic management of affected patients based on current evidence and best practice. ${ }^{7}$

This study found that there are many misperceptions on GDM that persisted in communities such as GDM is never cured properly. Some pregnant women mentioned GDM would cure after delivery. Another study finding also supports these findings where the misperceptions on GDM persist in different ethnic communities. ${ }^{21}$

Lack of community awareness on GDM and limited communication with government health care providers regarding GDM is one of the significant constraints identified in this study which is similar to a study from Western-Pacific. ${ }^{22}$ GDM is a challenge to the health systems management especially for the LMICs, more specifically in the rural areas with multi-dimensional resource constrains. Awareness and information dissemination for GDM management both for the community including the pregnant women and the lower level healthcare providers could be effective as suggested by other studies. ${ }^{23}$

\section{Conclusions}

The perception of the community people on GDM needs to be enhanced. The community awareness of GDM is essential. GDM related Counseling during ANC is necessary to increase the knowledge and practices of the community. Policymakers need to address the community challenges on GDM. Particular community interventions on GDM surveillance and awareness programs are crucial to achieving the SDG goal.

\section{Data Sharing Statement}

Data is stored at the CIPRB. Due to the sensitivity of the data (contains identifying information), permission is required from the Ethical Review Committee (ERC) of CIPRB, Dhaka, Bangladesh, for sharing data with a third party. Data can be requested from the CIPRB, who will contact the Ethical Committee to gain approval to share the data. The conditions for gaining data access are 
a formal request with a clear objective and official permission from the Ethical Committee. Please contact the corresponding author to request the data through email at info@ciprb.org.

\section{Funding}

The community based GDM detection and surveillance in Bangladesh intervention is financially supported by the World Diabetes Foundation (WDF).

\section{Disclosure}

The authors report no conflicts of interest in this work.

\section{References}

1. World Health Organization (WHO). Global report on diabetes. ISBN. 2016;978:88.

2. Nordisk N. Changing diabetes in Bangladesh through sustainable partnerships. Bluepr Change Program. 2012;4:1-24.

3. Akter S, Rahman MM, Abe SK, Sultana P. Prevalence of diabetes and prediabetes and their risk factors among Bangladeshi adults: a nationwide survey. Bull World Health Organ. 2014;92(3):204213A. doi:10.2471/BLT.13.128371

4. Jesmin S, Akter S, Akashi H, et al. Screening for gestational diabetes mellitus and its prevalence in Bangladesh. Diabetes Res Clin Pract. 2014;103(1):57-62. doi:10.1016/j.diabres.2013.11.024

5. Sayeed MA, Mahtab H, Khanam PA, Begum R, Banu A, Azad Khan AK. Diabetes and hypertension in pregnancy in a rural community of Bangladesh: a population-based study. Diabet Med. 2005;22 (9):1267-1271. doi:10.1111/j.1464-5491.2005.01600.x

6. Biswas RT. Risk Factors and Pregnancy Outcomes Among Gestational Diabetic Mothers: A Hospital Based Study in Bangladesh. Norway: University of Oslo; 2006.

7. Ahmed SM, Adams AM, Chowdhury M, Bhuiya A. Changing health-seeking behaviour in Matlab, Bangladesh: do development interventions matter? Health Policy Plan. 2003;18(3):306-315. doi:10.1093/heapol/czg037

8. Unicef. Maternal and Neonatal Health in Bangladesh. 2009.

9. National Institute of Population Research and Training (NIPORT), MEASURE Evaluation, icddr,b. Bangladesh Maternal Mortality and Health Care Survey 2010. Dhaka, Bangladesh; 2012.
10. NIPORT, Mitra and Associates, ICF International. Bangladesh Demographic and Health Survey, 2011. 2013.

11. WHO. Pregnant Women Must Be Able to Access the Right Care at the Right Time. 2016.

12. Kim C. Gestational diabetes: risks, management, and treatment options. Int J Women's Health. 2010;2(1):339-351. doi:10.2147/ IJWH.S13333

13. Bhavadharini B, Uma R, Saravanan P, Mohan V. Screening and diagnosis of gestational diabetes mellitus - relevance to low and middle income countries. Clin Diabetes Endocrinol. 2016;2(1):1-8. doi:10.1186/s40842-016-0031-y

14. Shriraam V, Mahadevan S, Rani S, Sathiyasekaran BWC. Awareness of gestational diabetes mellitus among antenatal women in a primary health center in South India. Indian J Endocrinol Metab. 2013;17 (1):146. doi:10.4103/2230-8210.107861

15. Khiyali Z, Manoochri M, Jeihooni AK, Heydarabadi AB, Mobasheri F. Educational intervention on preventive behaviors on gestational diabetes in pregnant women: application of health belief model. Int J Pediatr. 2017;5(5):2833-2838.

16. World Health Organization (WHO). WHO Recommendation on Antenatal Care for Positive Pregnancy Experience. 2016:152

17. Irving S. Interviewing as Qualitative Research - a Guide for Researchers in Education and the Social Sciences. Teach Coll Columbia Univ USA; 2006.

18. Boyatzis RE. Transforming Qualitative Information: Thematic Analysis and Code Development. Sage; 1998.

19. Meloncelli N, Barnett A, Pelly F, de Jersey S. Diagnosis and management practices for gestational diabetes mellitus in Australia: cross-sectional survey of the multidisciplinary team. Aust N Z J Obstet Gynaecol. 2018;59(2):208-14.

20. Utz B, Assarag B, Essolbi A, Barkat A, Delamou A, De Brouwere V. Knowledge and practice related to gestational diabetes among primary health care providers in Morocco: potential for a defragmentation of care? Prim Care Diabetes. 2017;11(4):389-396. doi:10.1016/j. pcd.2017.04.005

21. Yuen L. Gestational diabetes mellitus: challenges for different ethnic groups. World J Diabetes. 2015;6(8):1024. doi:10.4239/wjd.v6. i 8.1024

22. Price LA, Lock LJ, Archer LE, Ahmed Z. Awareness of gestational diabetes and its risk factors among pregnant women in Samoa. Hawaii J Med Public Health. 2017;76(2):48-54.

23. Harrison AL, Taylor NF, Frawley HC, Shields N. Women with gestational diabetes mellitus want clear and practical messages from credible sources about physical activity during pregnancy: a qualitative study. J Physiother. 2019;65(1):37-42. doi:10.1016/j. jphys.2018.11.007

\section{Publish your work in this journal}

Diabetes, Metabolic Syndrome and Obesity: Targets and Therapy is an international, peer-reviewed open-access journal committed to the rapid publication of the latest laboratory and clinical findings in the fields of diabetes, metabolic syndrome and obesity research. Original research, review, case reports, hypothesis formation, expert opinion and commentaries are all considered for publication. The manuscript management system is completely online and includes a very quick and fair peer-review system, which is all easy to use. Visit http://www.dovepress.com/testimonials.php to read real quotes from published authors. 